\title{
Weather factors affecting the male mate-locating tactics of the small copper butterfly (Lepidoptera: Lycaenidae)
}

\author{
JuN-YA IDE* \\ Laboratory of Insect Ecology, Graduate School of Agriculture, Kyoto University, Kyoto 606-8502, Japan
}

Key words. Activity pattern, Lycaena phlaeas daimio, mate-locating tactics, patrolling, perching, thermoregulation, weather

\begin{abstract}
Males of the small copper butterfly, Lycaena phlaeas daimio, exhibit two mate-locating tactics: patrolling and perching. Field investigations were conducted to determine the biotic and abiotic factors affecting the mate-locating behaviour of male $L$. phlaeas. Patrolling was often observed when light intensity was high. Perching was performed throughout the day regardless of environmental conditions, but the chasing of passing insects increased at high light intensities. The activity patterns of the males were not affected by those of the females. The thoracic temperatures of patrolling males were lower than those of perching males under cool conditions, suggesting that patrolling males lose heat more easily. In contrast, perching males may more easily regulate their body temperature to a suitable level as they fly for shorter periods and can bask while waiting for mates. These results highlight several reasons (i.e., heat loss, energetic costs) why males patrol when weather conditions are favourable.
\end{abstract}

\section{INTRODUCTION}

Animals adopt various alternative tactics in their reproductive behaviour (Gross, 1996; Oliveira et al., 2008). In butterflies, the males of various species use alternative strategies for locating mates, which are classified as patrolling and perching (Scott, 1974; Dennis \& Shreeve, 1988; Wiklund, 2003). Patrolling involves the active search for receptive females over a wide area, whereas perching involves sitting-and-waiting for females. During perching, males are stationary and wait for a passing female. This tactic includes territorial behaviour, lekking and hill-topping. In some butterflies, one individual can perform both types of behaviour and can alternate between the two depending on the conditions (Shreeve, 1992). Ide \& Kondoh (2000) used a game model of the sexes to investigate the conditions affecting the switching between mate-locating tactics. Their model predicted that a particular tactic is favoured when its costs are lower and its searching efficiency is higher compared to the other tactic (Ide \& Kondoh, 2000). Various factors appear to affect the switching of mate-locating tactics, such as meteorological conditions (Wickman, 1985, 1988), abundance and behaviour of receptive females (Dennis \& Williams, 1987; Ide, 2004) and abundance of rival males (Alcock \& O’Neill, 1986; Peixoto \& Benson, 2009). However, most previous studies examine factors affecting either the cost or the searching efficiency of the two tactics, whereas few studies simultaneously evaluate both factors.

The activity level of insects depends on body temperature (Heinrich, 1993), which is greatly affected by abiotic environmental factors; in turn, mate-locating behaviour is also influenced by the thermal environment (e.g.,
Larsson, 1991; Willmer, 1991; Rutowski et al., 1994; Kemp \& Rutowski 2001; Ide, 2002). Flight of butterflies is highly constrained by temperature and they can spend more time in flight at high ambient temperatures (Heinrich, 1986). Therefore, it is predicted, on the basis of costs, that male butterflies are likely to favour a perching strategy at low temperatures and a patrolling strategy at high temperatures (e.g., Wickman, 1985, 1988). However, female butterflies are also affected by ambient temperatures. Perching males more frequently encounter females when they actively move around (Reynolds, 2006). If males perch when the temperature is low mating would rarely occur if the flight activity of females is, as in males, low under those conditions. At low temperatures, therefore, males are predicted to encounter more females by patrolling than by perching. Thus, in terms of searching efficiency, it is likely that the mate-locating tactics of males correspond to the activity patterns of females.

Males of the purple-edged copper butterfly Lycaena hippothoe L. both patrol and perch and the time they spend patrolling increases when the weather is calm and warm (Fischer \& Fiedler, 2001). However, these authors did not measure the body temperatures of the butterflies or examine the effects of the temporal activity patterns of female butterflies on male behaviour; therefore, the ecological processes underlying the relationship between mate-locating behaviour and weather conditions, or female behaviour, remain unclear.

In the related species L. phlaeas daimio Seitz, males are recorded as only perching when seeking females (Suzuki, 1976; Fukuda et al., 1984), but a preliminary study revealed that they also switch between perching and patrolling (J.-Y. Ide, pers. observ.). Here, whether the

\footnotetext{
* Present address: Department of Education and Creation Engineering, Kurume Institute of Technology, 2228-66 Kamitsu-machi, Kurume, Fukuoka 830-0052, Japan; e-mail: idejy@cc.kurume-it.ac.jp
} 
(a)

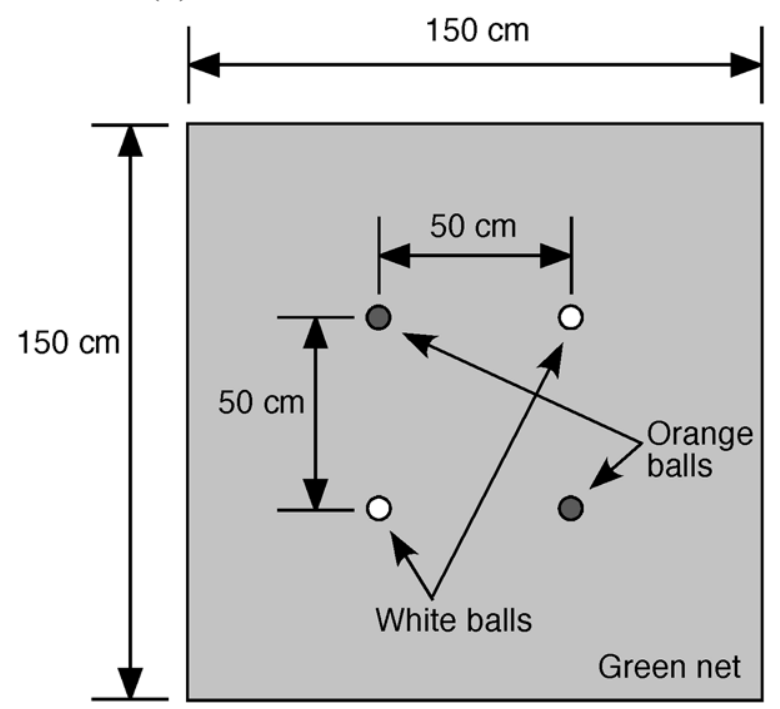

(b)

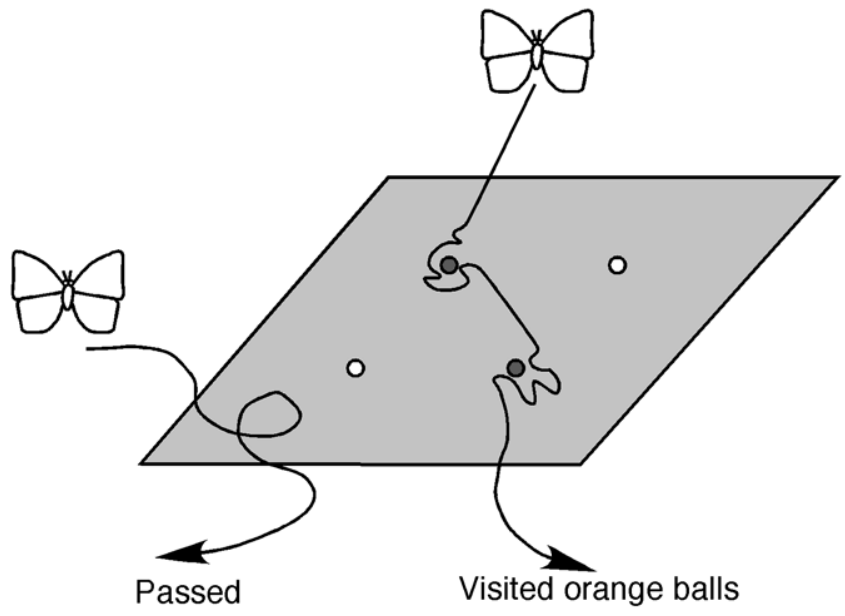

Fig. 1. Method used to study the patrolling by males of Lycaena phlaeas. (a) Placement of models. (b) Typical flight paths of $L$. phlaeas.

mate-locating behaviour of male L. phlaeas is determined by male thermoregulation (i.e., the cost of each tactic) or by female activity patterns (i.e., the searching efficiency of each tactic) was studied. First, the diurnal patterns of patrolling and perching as well as the meteorological factors affecting these patterns were investigated. Next, the patterns in the male mate-locating tactics and female activity were compared. Finally, the body temperatures of male butterflies were measured in order to verify that thermoregulation affected the choice of mate-locating tactics.

\section{MATERIAL AND METHODS}

\section{Study species and site}

The small copper butterfly L. phlaeas daimio (Lepidoptera: Lycaenidae) is a Japanese subspecies of a widespread Palaearctic butterfly L. phlaeas L. and is the only species of Lycaena in Japan (Fukuda et al., 1984). This species inhabits grasslands, and its larval host plants are Rumex acetosa $\mathrm{L}$. and $R$. japonicus Houtt. Field investigations were conducted in a small meadow ( $0.2 \mathrm{ha})$ along the banks of the Iwakura-gawa River in Kyoto, central Japan $\left(135^{\circ} 47^{\prime} \mathrm{E}, 35^{\circ} 3^{\prime} \mathrm{N}, 100 \mathrm{~m}\right.$ above sea level) from 2004 to 2008 . Throughout this area, host plants and nectar resources were distributed almost uniformly and the height of the herbaceous vegetation varied between approximately 70 and $90 \mathrm{~cm}$. Adults of L. phlaeas are present from April to November and there are several generations each year at this site. The study site was maintained as grassland by mowing once a year in August.

\section{Patrolling}

To determine the conditions under which males patrol, their diurnal activity patterns of patrolling were recorded on 7, 8, 12 and 15 May 2008. Butterflies fly for a variety of reasons; therefore, a flying butterfly was considered to be patrolling for mates if it visited a model of $L$. phlaeas. Ping-pong balls $(40 \mathrm{~mm}$ diameter) painted orange were used as models. A green square net $($ side $=150 \mathrm{~cm}$ ) was spread out in the meadow, and two orange and two white (controls) ping-pong balls were placed in the centre of the net at the corners of a $50-\mathrm{cm}$ square. The same coloured balls were placed in diagonally opposite corners of the square (Fig. 1a). This square plot was placed randomly in sunny areas at the study site and its positions changed each day. When a $L$. phlaeas individual visited the models, the time and colour of the ball were recorded, and if possible the butterfly was caught. Captured butterflies were sexed and released immediately. When a butterfly visited both the orange and white coloured balls the colour of the ball visited first was recorded. When a butterfly flew over the green net but did not visit any of the balls, the sex of the butterfly was also determined (Fig. 1b). During the field study (0700 to $1700 \mathrm{~h}$ ), air temperature, light intensity, relative humidity and wind velocity were recorded every $15 \mathrm{~min}$. Relative humidity readings were converted to vapour pressure deficit (VPD) using equations in Lowe (1977).

\section{Perching}

A sitting male butterfly was considered to be perching if it exhibited chasing flight upon encountering individuals. Between April and July in 2004 to 2008, the continuous focal sampling method (Martin \& Bateson, 1986) was used to determine the conditions under which males perform the perching tactic. Male butterflies were captured using a soft insect net, marked with a number on the undersurface of both hind wings using a felttipped pen and then released. The following day any marked individual encountered was followed until lost. When an insect came within a radius of $50 \mathrm{~cm}$ of the focal butterfly it was considered to have passed the focal butterfly. The species of the passing insect and whether the focal butterfly chased it were recorded. Air temperature, light intensity, relative humidity and wind velocity were recorded every $15 \mathrm{~min}$. These observations took place between 0700 and $1700 \mathrm{~h}$ on non-rainy days. Only data for focal butterflies that could be followed for more than 10 min were used in the analyses. A total of 50 individuals were observed for a total of approximately $70 \mathrm{~h}$.

\section{Flight activity patterns of females}

The diurnal flight activity pattern of female butterflies was determined for comparison with those of perching and patrolling males. Continuous focal sampling of female butterflies was also conducted as described above. All activities of focal individuals were recorded on an IC recorder. A total of 36 individuals were observed for a total of approximately $72.5 \mathrm{~h}$. 


\section{Body temperature}

During the flight season of L. phlaeas in 2004 to 2008, the thoracic temperature of male butterflies was measured using a portable digital thermometer (Model TX1002, Yokogawa Electric Works Ltd.) fitted with a hypodermic thermocouple probe (0.2 mm diameter). After locating a male butterfly and recording its behaviour, it was caught with an insect net, immediately held with its wings closed over its back and the probe inserted into the centre of its thorax from the ventral side. The time from capture to measurement of the temperature never exceeded $10 \mathrm{~s}$.

Male behaviour was classified as either: patrolling, perching or other. A male was considered to be patrolling if it flew a long distance and perching if it quickly flew towards an approaching flying insect. After measuring the thoracic temperature, the butterfly was released. Air temperature, light intensity, relative humidity and wind velocity at the site were measured immediately after a butterfly's temperature was measured.

\section{Statistical analyses}

Statistical analyses were conducted using $\mathrm{R}$ version 2.8.1 ( $\mathrm{R}$ Development Core Team, 2008).

\section{Patrolling}

The orange colour of the L. phlaeas models may also attract butterflies searching for nectar. If $L$. phlaeas sometimes mistakes orange balls for flowers, they would also mistake balls of other colours for flowers. As the white flowers of clover, Trifolium repens L., were the main source of nectar for L. phlaeas in the meadow, the expectation was that they would visit white balls as frequently or more frequently than orange balls and if they did not mistake ping-pong balls for flowers they would not visit white balls. Thus, binomial tests were used to examine whether butterflies visited orange balls more frequently than white balls. If the visits to orange balls resulted from butterflies mistaking the balls for conspecifics, then the majority of orangeball visitors would be males. Fisher's exact probability tests were used to test whether the male ratio of orange-ball visitors was higher than that of white-ball visitors and of passing individuals.

To evaluate the factors affecting the number of butterflies visiting orange balls, a generalised linear mixed model (GLMM) with a Poisson error structure and a log link function was used. The dependent variable was the number of butterflies visiting orange balls; time of day, air temperature, light intensity, VPD and wind velocity were the independent variables. Since this experiment was conducted just after the peak of the flight season of the first generation of the year, daily total number of L. phlaeas observed declined day by day. To control for effects due to the changes in daily population size, sampling date was included in the model as a random factor. Model selection was performed using Akaike's information criterion (AIC) in a backward elimination procedure.

\section{Perching}

To determine the factors affecting whether male butterflies chased passing insects a GLMM with a binomial error structure and a logit link function was used. The dependent variable was whether a focal male chased each passing insect (chased $=1$, did not chase $=0$ ); time of day, air temperature, light intensity, VPD and wind velocity were the independent variables, and the focal male was a random factor. Model selection was performed using $\mathrm{AIC}$ in a backward elimination procedure.

Flight activity patterns of females

To evaluate the factors affecting the flight activity of female butterflies a GLMM with a binomial error structure and a logit link function was used. Focal sampling (continuous recording) data were divided into 15 -min units of observation, and the proportion of time spent in flight by a focal female during each unit was calculated. When the units of observation were shorter than $10 \mathrm{~min}$, the data point was not included in the analysis. Because the units of observation obtained from a focal sampling data set were not independent, the focal sampling data set (i.e., the focal individual) was included in the model as a random factor to control for effects due to non-independence. The dependent variable was the proportion of time spent flying by a focal female; time of day, air temperature, light intensity, VPD and wind velocity were the independent variables. Model selection was performed using AIC in a backward elimination procedure.

\section{Body temperature}

A general linear model was used to evaluate the factors affecting thoracic temperature. The dependent variable was thoracic temperature of male butterflies classified by behaviour; air temperature, light intensity, VPD and wind velocity were the independent variables. Model selection was performed using AIC in a backward elimination procedure. An analysis of covariance (ANCOVA) was used to test for differences in the thoracic temperatures of the males that patrolled, perched, or indulged in other types of behaviour, with air temperature and light intensity as covariates.

\section{RESULTS}

\section{Patrolling}

A total of 381 L. phlaeas visited orange models but only seven visited white models (binomial test, $P<0.001$; Table 1). Except for one individual, all orange-model visitors, whose sex was determined, were males. The male ratio of orange-model visitors was significantly higher than that of white-model visitors and passing individuals (Table 1). Therefore, most orange-model visitors were assumed to be patrolling.

TABLE 1. The number and male ratio of Lycaena phlaeas daimio that visited each model or passed over the models.

\begin{tabular}{lccc}
\hline Model & $\begin{array}{c}\text { No. butterflies } \\
\text { observed }\end{array}$ & $\begin{array}{c}\text { No. butterflies } \\
\text { sexed }\end{array}$ & Male ratio \\
\hline Orange & 381 & 174 & 0.994 \\
White & 7 & 5 & 0.600 \\
Passed & 38 & 11 & 0.364 \\
\hline
\end{tabular}

The number of L. phlaeas visiting orange models increased around noon, but the diurnal patterns varied greatly between days (Fig. 2). Light intensity and time of day were included as explanatory variables by model selection (Table 2). In particular, the estimated coefficient for light intensity was significant and positive, indicating that male L. phlaeas patrolled when it was sunny.

\section{Perching}

A total of 508 insects flew by the focal males (83 conspecifics, 425 individuals of other species). When the insect was a conspecific the male almost always chased the passing insect regardless of time of day (Fig. 3). No independent variable was included as a factor affecting whether a male chased a passing conspecific individual (Table 3). When other species passed, males also often chased the passing insect (Fig. 3). However, the fre- 


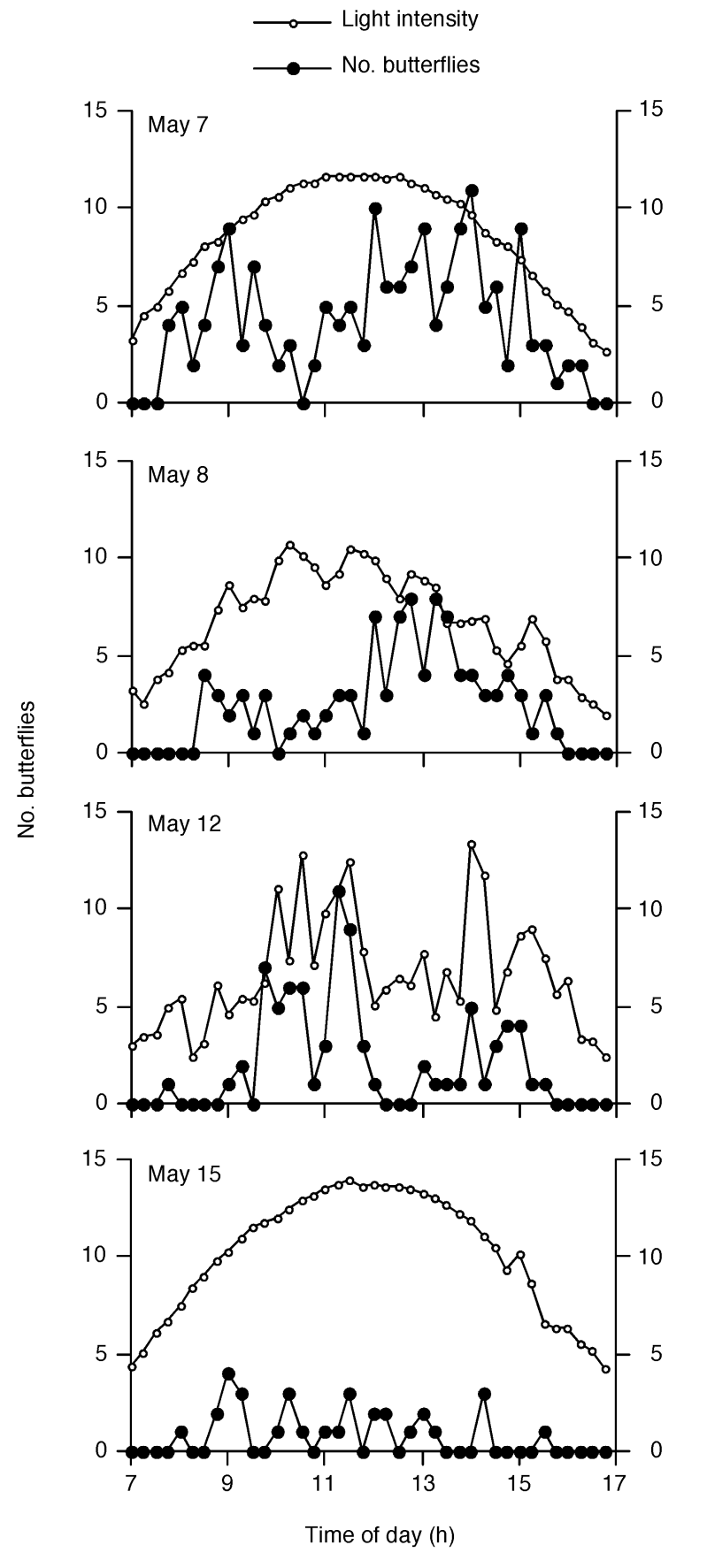

Fig. 2. Diurnal changes in light intensity and the number of Lycaena phlaeas visiting orange models each $15 \mathrm{~min}$ from 07 to $17 \mathrm{hr}$ on 7 th, 8th, 12th and 15th May.

quency of the chasing reaction to passing other species was lower than that to passing conspecifics (Fisher's exact probability test, $P<0.001$ ), especially early in the morning. Light intensity, VPD and time of day were selected as factors affecting whether a male chased other species (Table 3 ). The coefficients for light intensity and VPD were significant and positive (the coefficient for time of day was not significant), indicating that males of L. phlaeas frequently chased passing heterospecifics when it was sunny and the humidity was low.
TABLE 2. Summary of GLMM model selection of the factors determining the number of butterflies visiting orange models.

\begin{tabular}{lccrr}
\hline Variable & Coefficient & $\mathrm{SE}$ & $z$ & $P$ \\
\hline Intercept & -0.766 & 0.4717 & -1.624 & 0.104 \\
Light intensity & $1.431 \times 10^{-5}$ & $3.359 \times 10^{-6}$ & 4.260 & $<0.001$ \\
Time of day & & & & \\
8 & 0.122 & 0.354 & 0.346 & 0.729 \\
9 & -1.679 & 0.445 & -3.777 & $<0.001$ \\
10 & -0.394 & 0.325 & -1.214 & 0.225 \\
11 & -1.110 & 0.266 & -4.179 & $<0.001$ \\
12 & 0.274 & 0.219 & 1.249 & 0.212 \\
13 & -0.234 & 0.174 & -1.344 & 0.179 \\
14 & -0.248 & 0.154 & -1.613 & 0.107 \\
15 & 0.281 & 0.148 & 1.904 & 0.057 \\
16 & -0.170 & 0.138 & -1.230 & 0.219 \\
\hline
\end{tabular}

Flight activity patterns of females

Female flight activity was low throughout the day with the time spent in flight $2.1 \pm 0.3 \%$ of the total time observed $(N=287)$. Flight activity varied with the time of day, very low in the early morning and rapidly increasing to a maximum at $1000 \mathrm{~h}$, followed by a decline throughout the rest of the day (Fig. 4). The proportion of time spent flying by a female depended on light intensity, indicating that female flight activity increased when it was sunny; however, the coefficient for light intensity was not significant (coefficient $\pm \mathrm{SE}=1.721 \times 10^{-5} \pm$ $\left.1.177 \times 10^{-5}, z=1.461, P=0.144\right)$.

\section{Body temperature}

Air temperature and light intensity were selected as factors affecting the thoracic temperature of male $L$. phlaeas, regardless of their behaviour (Table 4). These results indicate that thoracic temperature increased with air temperature and solar radiation.

The thoracic temperature of males depended on their mate-locating behaviour under conditions of low air temperature and low solar radiation, and significant interactions were detected between behaviour and both air temperature and light intensity (ANCOVA; Fig. 5, Table 5). Under low air temperature and low solar radiation, perching males had the highest thoracic temperature, followed by patrolling males, while males engaged in other behaviour had the lowest thoracic temperatures.

\section{DISCUSSION}

Males of $L$. phlaeas exhibited patrolling and perching under different weather conditions. The number of patrolling individuals was greatly affected by weather, with most patrolling when it was sunny (Fig. 2, Table 2). In contrast, perching occurred throughout the day, including early morning and late afternoon, when patrolling was not observed (Fig. 3). The flight activity of females was not consistent with the daily patterns of male perching, but increased slightly at high light intensities, similar to the patrolling by males. These results conflict with the prediction that males would patrol when females did not fly, i.e., the hypothesis that the alternative tactics of male $L$. phlaeas have been selected to efficiently encounter 


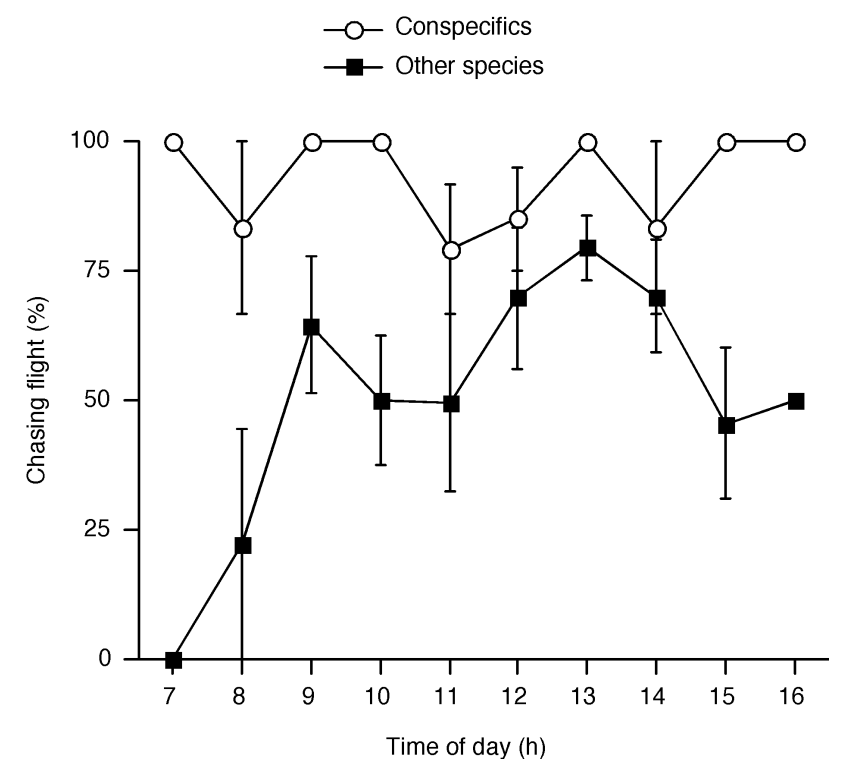

Fig. 3. Diurnal changes in the percentage of Lycaena phlaeas males that chased passing conspecifics or other insect species. Means $( \pm \mathrm{SE})$ of chasing rate of males are shown.

females by adapting their activity patterns to female behaviour.

That each tactic is associated with different environmental conditions can be accounted for in part by the need for thermoregulation in males. For flight butterflies often require a body temperature higher than ambient air temperature (Watt, 1968; Shelly \& Ludwig, 1985; Ohsaki, 1986; Srygley, 1994; Ide, 2002). Because both the mate-locating tactics of $L$. phlaeas males involve active flight it is likely that when L. phlaeas males are seeking mates they need to maintain a high body temperature. This hypothesis is supported by the fact that the thoracic temperatures of both patrolling and perching males were higher than those of males engaging in other behaviour, such as feeding and resting. However, when the

TABLE 3. Summary of GLMM model selection of the factors determining the number of males indulging in chasing flights.

\begin{tabular}{lccccc}
\hline Passing insect & Variable & Coefficient & SE & $z$ & $P$ \\
\hline Conspecifics & Intercept & 2.681 & 0.801 & 3.349 & $<0.001$ \\
Other species & Intercept & -4.421 & 16.56 & -0.267 & 0.790 \\
& Light & 1.557 & 6.339 & & \\
& intensity & $\times 10^{-5}$ & $\times 10^{-6}$ & 2.456 & 0.014 \\
& Vapour pres- & & & \\
sure deficit & 0.988 & 0.268 & 3.683 & $<0.001$ \\
& Time of day & & & & \\
& 8 & 5.294 & 82.00 & -0.065 & 0.949 \\
9 & -6.003 & 86.43 & -0.069 & 0.945 \\
& 10 & 4.201 & 75.04 & 0.056 & 0.955 \\
& 11 & -4.326 & 55.71 & -0.078 & 0.938 \\
& 12 & 2.053 & 35.56 & 0.058 & 0.954 \\
& 13 & -0.337 & 19.33 & -0.017 & 0.986 \\
& 14 & -0.534 & 8.733 & -0.061 & 0.951 \\
& 15 & 0.983 & 3.123 & 0.315 & 0.753 \\
& 16 & 0.309 & 0.892 & 0.346 & 0.729 \\
\hline
\end{tabular}

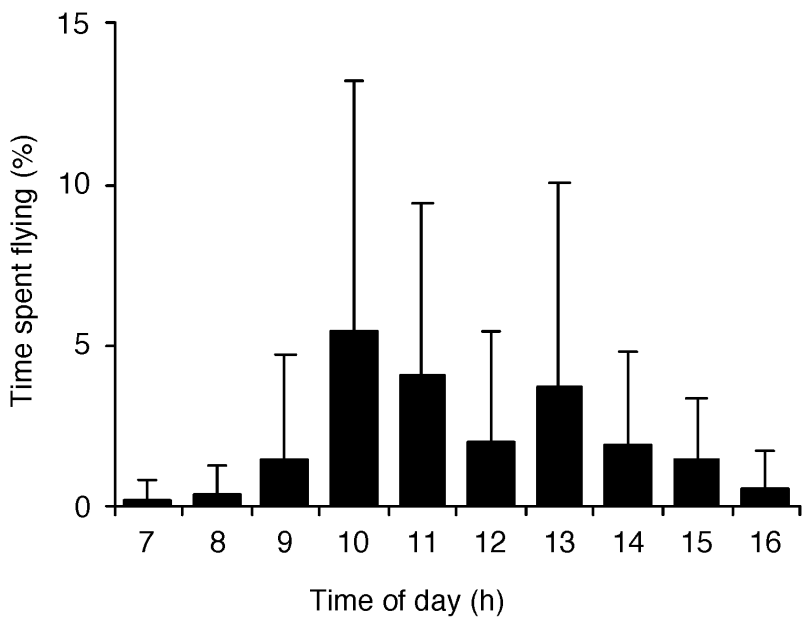

Fig. 4. Diurnal changes in the percentage of time spent flying by Lycaena phlaeas females (mean $\pm \mathrm{SE})$. Mean sample size $( \pm$ $\mathrm{SD})$ for each value was $28.7 \pm 5.9$.

body temperatures of perching and patrolling males of $L$. phlaeas were compared, patrolling males had lower thoracic temperatures when conditions were cool (Fig. 5). The body temperature of butterflies declines during flight via convective cooling (Tsuji et al., 1986; Wickman, 1988). For example, in the speckled wood butterfly Pararge aegeria L., patrolling butterflies lose heat more easily than perching ones, because patrolling individuals fly for longer periods (Van Dyck \& Matthysen, 1998). Therefore, the difference in body temperature between tactics may be caused by the decrease in body temperature of males while patrolling. Many butterfly species raise their body temperature by basking, which enables them to fly (Clench, 1966; Kingsolver, 1983; Heinrich, 1986; Pivnick \& McNeil, 1986; Dreisig, 1995; Ide, 2000). Therefore, light intensity is sometimes a limiting factor for butterfly flight (Guppy, 1986; Pivnick \& McNeil, 1987; Roland, 2006). Patrolling by L. phlaeas was observed under higher light intensity than perching, suggesting that light intensity was indeed a limiting factor for patrolling and that the threshold was substantially

TABLE 4. Summary of model selection in the general linear model of the factors determining thoracic temperature.

\begin{tabular}{lcccc}
\hline Variables & Coefficient & SE & $t$ & $P$ \\
\hline Patrolling & & & & \\
Intercept & 14.86 & 1.538 & 9.664 & $<0.001$ \\
Air temperature & 0.631 & 0.071 & 8.943 & $<0.001$ \\
Light intensity & $4.162 \times 10^{-5}$ & $6.990 \times 10^{-6}$ & 5.955 & $<0.001$ \\
Wind velocity & -0.670 & 0.486 & -1.379 & 0.18 \\
Perching & & & & \\
Intercept & 18.32 & 1.022 & 17.930 & $<0.001$ \\
Air temperature & 0.575 & 0.041 & 13.858 & $<0.001$ \\
Light intensity & $2.750 \times 10^{-5}$ & $6.375 \times 10^{-6}$ & 4.314 & $<0.001$ \\
Others & & & & \\
Intercept & 9.237 & 0.832 & 11.11 & $<0.001$ \\
Air temperature & 0.806 & 0.037 & 21.50 & $<0.001$ \\
Light intensity & $5.686 \times 10^{-5}$ & $5.414 \times 10^{-6}$ & 10.50 & $<0.001$ \\
\hline
\end{tabular}




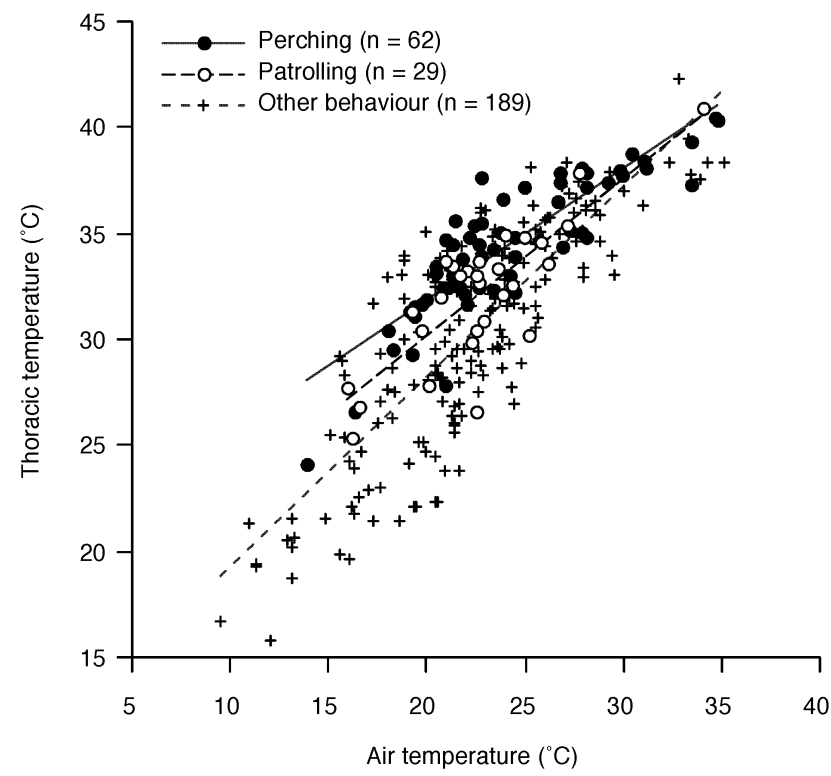

Fig. 5. Thoracic temperature of Lycaena phlaeas males that had just either been patrolling, perching or involved in other behaviour. Air temperature is shown on the x-axis. Fitted lines were estimated by linear regression of thoracic temperature on air temperature.

higher than that for simple flight because body temperature decreases during patrolling.

Male L. phlaeas spend at most $5 \%$ of their time in flight (J.-Y. Ide, unpubl. data), which indicates they do not patrol for long periods of time. Between intervals of patrolling, males perched, and as a result, perching was observed throughout the day. Therefore, patrolling may be used in combination with perching, as in L. hippothoe (Fischer \& Fiedler, 2001). Maintaining body temperature at a suitable level may be easier for perching males as they only fly for short periods and they can bask while waiting for mates. Moreover, males incur almost no costs by not taking off, which may be why they perch even if few females fly when temperatures are low. However, even if males can perch at any time and so maintain their body temperature, the cost of chasing increases when air temperature declines. In fact, the take-off performance of butterflies declines when it is cool (Berwaerts \& Van Dyck, 2004). At low light intensities, the chasing reaction to passing heterospecifics was minimal (Fig. 3, Table 3), which possibly reflects the high costs of chasing when it is difficult to maintain a high body temperature. Males

TABLE 5. Summary of the ANCOVA of the effect of behaviour, air temperature and light intensity on the thoracic temperature of males of Lycaena phlaeas.

\begin{tabular}{lcccc}
\hline Variable & Mean square & df & $F$ & $P$ \\
\hline Behaviour & 48.33 & 2 & 10.987 & $<0.001$ \\
Air temperature & 3020.87 & 1 & $686.729<0.001$ \\
Light intensity & 664.69 & 1 & $151.103<0.001$ \\
Behaviour $\times$ air temperature & 27.08 & 2 & 6.155 & 0.002 \\
Behaviour $\times$ light intensity & 20.02 & 2 & 4.550 & 0.011 \\
Residuals & 4.40 & 271 & & \\
\hline
\end{tabular}

may avoid the costly task of taking off until they ascertain that a flying insect is a conspecific.

Perching increased when it was dry. One interpretation of this is that low humidity improves the flight efficiency of L. phlaeas males. The relationship between insect flight and humidity has not been thoroughly examined, but several studies report that the flight activity of insects increases when it is dry (McGiffen \& Meyer, 1986; Zhang \& Shipp, 1998; Shipp \& Zhang, 1999). High humidity might be unsuitable for butterfly flight because the wings absorb water and become heavier or due to the increased viscosity of the air. Further study is necessary to clarify the mechanisms underlying the increase in flight activity of butterflies when it is dry. Another possibility is that L. phlaeas males chose dryer spots to perch while waiting for mates. However, males almost always perched at the top of a blade of grass, and the height of the site did not differ regardless of whether they chased passing individuals or not (J.-Y. Ide, unpubl. data). Therefore, it is unlikely that the males perch at dry sites only when they were waiting for mates.

The results presented here beg the question: Why is the mate-locating behaviour of L. phlaeas males affected by thermoregulation and not by the activity patterns of females? One reason may be the low predictability of the spatial distribution of sexually receptive females. Females of many butterfly species mate immediately after emergence; thus, the possibility that receptive females will be found close to where they emerge (in most cases, around host plants) is high (Rutowski, 1991). Male butterflies can save energy if they only search for mates around host plants. Therefore, if the predictability of the distribution of receptive females is high, males may benefit by adapting their mate-locating behaviour to the temporal behavioural patterns of females as it is likely to increase their efficiency in searching for receptive mates. For example, the small cabbage white butterfly, Pieris rapae crucivora Boisduval, emerges in the early morning, and males patrol around host plants when the receptive females are emerging from pupation sites under the dense leaves of host plants (Hirota et al., 2001). Although it is cool in the early morning, and males have difficulty flying at this time (Hirota \& Obara, 2000), the costs for the males may not be very high as they do not need to search an extensive area. In contrast, female L. phlaeas copulate 2-4 days after emergence (Suzuki, 1978; Watanabe \& Nishimura, 2001). Female dispersal after emergence reduces the predictability of the distribution of receptive females; thus, males must fly greater distances to find females. As a result, the cost of patrolling increases. In this case, the patrolling may not be cost effective, even if males encounter more receptive females than when perching.

In addition, the operational sex ratio of $L$. phlaeas is always skewed notably toward males because a female mates only once in its lifetime (Watanabe \& Nishimura, 2001). This may be another reason that the mate-locating behaviour of $L$. phlaeas males is not affected by female activity patterns. Members of the more numerous sex 
must compete for access to the less numerous sex (Jiggins et al., 2000). Therefore, they would be favoured to select a mate-locating tactic with higher searching efficiency (usually a patrolling tactic), even if the tactic has higher costs (Hammerstein \& Parker, 1987). This is supported by the fact that the male is usually the sex that actively searches for mates (Kokko \& Wong, 2007). However, if the sex ratio is strongly skewed, the competition between members of the more numerous sex is intense and the variance in mating success is great. In this situation, it is advantageous for members of the more numerous sex to wait for an opportunity to mate and thereby spread the risk in time. Theoretical models predict that some individuals of the more numerous sex either stop searching for mates or change their tactic to one with lower costs until the costs of locating mates decline (Ide \& Kondoh, 2000; Kondoh \& Ide, 2003). In short, the skewed operational sex ratio of $L$. phlaeas may have led to the evolution of the strategy in which the males patrol only when weather conditions are favourable, which reduces the costs of patrolling.

Population density is thought to be one of the major factors determining mate-locating tactics (Scott, 1974; Wickman \& Rutowski, 1999; Kokko \& Rankin, 2006). In insects, there is a tendency for males to patrol at high population densities and to sit and wait for mates at low densities (Baughman et al., 1988; Alcock, 1994). A low population density would prolong the time from when females become receptive to when they mate, which results in female sperm limitation and may account for why population density influences mate-locating tactics (Wickman \& Rutowski, 1999; Kokko \& Wong, 2007). In Lepidoptera females generally suffer the cost of a decline in fecundity when mating is delayed (Wenninger \& Averill, 2006). Therefore, at low population densities, which commonly results in delayed mating, active matesearching by females and waiting by males would be favoured. In this study, the population density of $L$. phlaeas was not measured. However, it seemed to be very high, judging from the number of patrolling males (Fig. 2). Although this suggests that patrolling was favoured at this site, males mainly perched if the weather conditions were unfavourable. Overall, the results of this study are robust even if the population density was low.

In some insects that hold mating territories the territory is abandoned when males are abundant (Alcock \& O’Neill, 1986; Alcock, 1994). This is explained as being due to the costs of territory defence, which increase sharply when the incidence of invasions by rival males increases (Schoener, 1983; Alcock \& O’Neill, 1986). However, in some butterflies, the abundance of males does not affect the mate-locating tactic adopted (Wickman, 1988; Kemp, 2001). The perching tactic of $L$. phlaeas is seemingly a territorial behaviour. However, chasing is considered to be the means by which they determine the sex of a passing insect, not part of territorial behaviour (Suzuki, 1976). Therefore, it is unlikely that the mate-locating tactics of male L. phlaeas are greatly affected by the abundance of rival males.
ACKNOWLEDGEMENTS. I am grateful to N. Ohsaki for his helpful comments on the manuscript. This study was partly supported by JSPS Research Fellowship for Young Scientists (no. 16-380).

\section{REFERENCES}

Alcock J. 1994: Alternative mate-locating tactics in Chlosyne califolnica (Lepidoptera, Nymphalidae). Ethology 97: 103-118.

Alcock J. \& O’Neill K.M. 1986: Density-dependent mating tactics in the Grey hairstreak, Strymon melinus (Lepidoptera: Licaenidae). J. Zool. 209: 105-113.

Baughman J.F., Murphy D.D. \& Ehrlich P.R. 1988: Population structure of a hilltopping butterfly. Oecologia 75: 593-600.

Berwaerts K. \& VAN Dyck H. 2004: Take-off performance under optimal and suboptimal thermal conditions in the butterfly Pararge aegeria. Oecologia 141: 536-545.

ClenCH H.K. 1966: Behavioral thermoregulation in butterflies. Ecology 47: 1021-1034.

Dennis R.L.H. \& Shreeve T.G. 1988: Hostplant-habitat structure and the evolution of butterfly mate-locating behaviour. Zool. J. Linn. Soc. 94: 301-318.

DenNis R.L.H. \& WiLliams W.R. 1987: Mate location behavior of the large skipper butterfly Ochlodes venata: flexible strategies and spatial components. J. Lepid. Soc. 41: 45-64.

DREISIG H. 1995: Thermoregulation and flight activity in territorial male graylings, Hipparchia semele (Satyridae), and large skippers, Ochlodes venata (Hesperiidae). Oecologia 101: 169-176.

FisCHER K. \& FIEDLER K. 2001: Resource-based territoriality in the butterfly Lycaena hippothoe and environmentally induced behavioural shifts. Anim. Behav. 61: 723-732.

Fukuda H., Hama E., KuzuYa T., Takahashi A., Takahashi M., Tanaka B., Tanaka H., Wakabayashi M. \& Watanabe Y. 1984: The Life Histories of Butterflies in Japan. Vol. 3. Hoikusha, Osaka, 373 pp. [in Japanese].

Gross M.R. 1996: Alternative reproductive strategies and tactics: diversity within sexes. Trends Ecol. Evol. 11: 92-98.

GuPPY C.S. 1986: The adaptive significance of alpine melanism in the butterfly Parnassius phoebus F. (Lepidoptera: Papilionidae). Oecologia 70: 205-213.

Hammerstein P. \& Parker G.A. 1987: Sexual selection: games between the sexes. In Bradbury J.W. \& Andersson M.B. (eds): Sexual Selection: Testing the Alternatives. Wiley, Chichester, pp. 119-142.

HeInRICH B. 1986: Thermoregulation and flight activity of a satyrine, Coenonympha inornata (Lepidoptera: Satyridae). Ecology 67: 593-597.

HeInRICH B. 1993: The Hot-Blooded Insects: Strategies and Mechanisms of Thermoregulation. Harvard University Press, Cambridge, $601 \mathrm{pp}$.

Hirota T. \& Obara Y. 2000: The influence of air temperature and sunlight intensity on mate-locating behavior of Pieris rapae crucivora. Zool. Sci. 17: 1081-1087.

Hirota T., Hamano K. \& Obara Y. 2001: The influence of female post-emergence behavior on the time schedule of male mate-locating in Pieris rapae crucivora. Zool. Sci. 18: $475-482$.

IDE J.-Y. 2000: Seasonal change in flight behaviour of the satyrine butterfly Lethe diana (Lepidoptera: Nymphalidae). Entomol. Sci. 3: 591-596.

IDE J.-Y. 2002: Seasonal changes in the territorial behaviour of the satyrine butterfly Lethe diana are mediated by temperature. J. Ethol. 20: 71-78. 
IDE J.-Y. 2004: Diurnal and seasonal changes in the matelocating behavior of the satyrine butterfly Lethe diana. Ecol. Res. 19: 189-196.

IdE J.-Y. \& KondOH M. 2000: Male-female evolutionary game on mate-locating behaviour and evolution of mating systems in insects. Ecol. Lett. 3: 433-440.

JigGins F.M., Hurst G.D.D. \& MAJERus M.E.N. 2000: Sex-ratiodistorting Wolbachia causes sex-role reversal in its butterfly host. Proc. R. Soc. Lond. (B) 267: 69-73.

Kemp D.J. 2001: Investigating the consistency of mate-locating behavior in the territorial butterfly Hypolimnas bolina (Lepidoptera: Nymphalidae). J. Insect Behav. 14: 129-147.

Kemp D.J. \& Rutowski R.L. 2001: Spatial and temporal patterns of territorial mate locating behaviour in Hypolimnas bolina (L.) (Lepidoptera: Nymphalidae). J. Nat. Hist. 35: 1399-1411.

Kingsolver J.G. 1983: Thermoregulation and flight in Colias butterflies: elevational patterns and mechanistic limitations. Ecology 64: 534-545.

Kокко H. \& Rankin D.J. 2006: Lonely hearts or sex in the city? Density-dependent effects in mating systems. Phil. Trans. $R$. Soc. (B) 361: 319-334.

Kокко H. \& Wong B.B.M. 2007: What determines sex roles in mate searching? Evolution 61: 1162-1175.

KonDOH M. \& IDE J.-Y. 2003: Evolution of periodicity in insect mate-seeking behaviour: a male-female coevolutionary game model. Anim. Behav. 65: 1013-1020.

LARSSON F.K. 1991: Some take it cool, some like it hot - a comparative study of male mate searching tactics in two species of Hymenoptera (Colletidae and Sphecidae). J. Therm. Biol. 16: $45-51$.

Lowe P.R. 1977: An approximating polynomial for computation of saturation vapor pressure. J. Appl. Meteorol. 16: 100-103.

Martin P. \& Bateson P. 1986: Measuring Behavior: An Introductory Guide. Cambridge University Press, Cambridge, 200 pp.

McGiffen M.E., JR. \& MeYer J.R. 1986: Effect of environmental factors on overwintering phenomena and spring migration of the plum curculio, Conotrachelus nenuphar (Coleoptera: Curculionidae). Environ. Entomol. 15: 884-888.

OHSAKI N. 1986: Body temperatures and behavioral thermoregulation strategies of three Pieris butterflies in relation to solar radiation. J. Ethol. 4: 1-9.

Oliveira R.F., TABorsky M. \& Brockmann H.J. 2008: Alternative Reproductive Tactics: An Integrative Approach. Cambridge University Press, Cambridge, UK, 507 pp.

Peixoto P.E.C. \& Benson W.W. 2009: Seasonal effects of density on territory occupation by males of the satyrine butterfly Paryphthimoides phronius (Butler 1867). J. Ethol. 27: 489-496.

Pivnick K.A. \& McNeil J.N. 1986: Sexual differences in the thermoregulation of Thymelicus lineola adults (Lepidoptera: Hesperiidae). Ecology 67: 1024-1035.

Pivnick K.A. \& McNeIL J.N. 1987: Diel patterns of activity of Thymelicus lineola adults (Lepidoptera: Hesperiidae) in relation to weather. Ecol. Entomol. 12: 197-207.

R Development Core Team 2008: R: A Language and Environment for Statistical Computing. R Foundation for Statistical Computing, Vienna, URL http://www.R-project.org.

REYNOLDS A.M. 2006: Optimal scale-free searching strategies for the location of moving targets: New insights on visually cued mate location behaviour in insects. Phys. Lett. (A) 360: 224-227.

RoLAND J. 2006: Effect of melanism of alpine Colias nastes butterflies (Lepidoptera: Pieridae) on activity and predation. Can. Entomol. 138: 52-58.
RUTOWSKI R.L. 1991: The evolution of male mate-locating behavior in butterflies. Am. Nat. 138: 1121-1139.

Rutowski R.L., Demlong M.J. \& Leffingwell T. 1994: Behavioural thermoregulation at mate encounter sites by male butterflies (Asterocampa leilia, Nymphalidae). Anim. Behav. 48: 833-841.

SCHOENER T.W. 1983: Simple models of optimal feedingterritory size: a reconciliation. Am. Nat. 121: 608-629.

Scotт J.A. 1974: Mate-locating behavior of butterflies. Am. Midl. Nat. 91: 103-117.

Shelly T.E. \& Ludwig D. 1985: Thermoregulatory behavior of the butterfly Calisto nubila (Satyridae) in a Puerto Rican forest. Oikos 44: 229-233.

ShIPP J.L. \& Zhang Y. 1999: Using greenhouse microclimate to improve the efficacy of insecticide application for Frankliniella occidentalis (Thysanoptera: Thripidae). J. Econ. Entomol. 92: 201-206.

Shreeve T.G. 1992: Adult behaviour. In Dennis R.L.H. (ed.): The Ecology of Butterflies in Britain. Oxford University Press, Oxford, pp. 22-45.

SRYGLEY R.B. 1994: Shivering and its cost during reproductivebehaviour in Neotropical owl butterflies, Caligo and Opsiphanes (Nymphalidae, Brassolinae). Anim. Behav. 47: 23-32.

SUZUKI Y. 1976: So-called territorial behaviour of the small copper, Lycaena phlaeas daimio Seitz (Lepidoptera, Lycaenidae). Kontyû 44: 193-204.

SUZUKI Y. 1978: Mate-avoiding behaviour in females of the small copper, Lycaena phlaeas daimio Seitz (Lepidoptera: Lycaenidae). Tyô Ga 29: 129-138 [in Japanese with English abstr.].

TsujI J.S., Kingsolver J.G. \& Watt W.B. 1986: Thermal physiological ecology of Colias butterflies in flight. Oecologia 69: 161-170.

VAN Dyck H. \& Matthysen E. 1998: Thermoregulatory differences between phenotypes in the speckled wood butterfly: hot perchers and cool patrollers? Oecologia 114: 326-334.

Watanabe M. \& Nishimura M. 2001: Reproductive output and egg maturation in relation to mate-avoidance in monandrous females of the small copper, Lycaena phlaeas (Lycaenidae). $J$. Lepid. Soc. 54: 83-87.

WatT W.B. 1968: Adaptive significance of pigment polymorphisms in Colias butterflies. I. Variation of melanin pigment in relation to thermoregulation. Evolution 22: 437-458.

WenNinger E.J. \& Averill A.L. 2006: Effects of delayed mating on reproductive output of female oriental beetle Anomala orientalis (Coleoptera: Scarabaeidae). Agric. For. Entomol. 8: 221-231.

WiCKMAN P.-O. 1985: The influence of temperature on the territorial and mate locating behaviour of the small heath butterfly, Coenonympha pamphilus (L.) (Lepidoptera: Satyridae). Behav. Ecol. Sociobiol. 16: 233-238.

Wickman P.-O. 1988: Dynamics of mate-searching behaviour in a hilltopping butterfly, Lasiommata megera (L.): the effects of weather and male density. Zool. J. Linn. Soc. 93: 357-377.

WickMan P.-O. \& RutowsKi R.L. 1999: The evolution of mating dispersion in insects. Oikos 84: 463-472.

WIKLUND C. 2003: Sexual selection and the evolution of butterfly mating systems. In Boggs C.L., Watt W.B. \& Ehrlich P.R. (eds): Butterflies: Ecology and Evolution Taking Flight. The University of Chicago Press, Chicago, pp. 67-90.

WILLMER P. 1991: Thermal biology and mate acquisition in ectotherms. Trends Ecol. Evol. 6: 396-399.

ZHANG Y. \& SHIPP J.L. 1998: Effect of temperature and vapor pressure deficit on the flight activity of Orius insidiosus (Hemiptera: Anthocoridae). Environ. Entomol. 27: 736-742.

Received December 1, 2009; revised and accepted March 1, 2010 